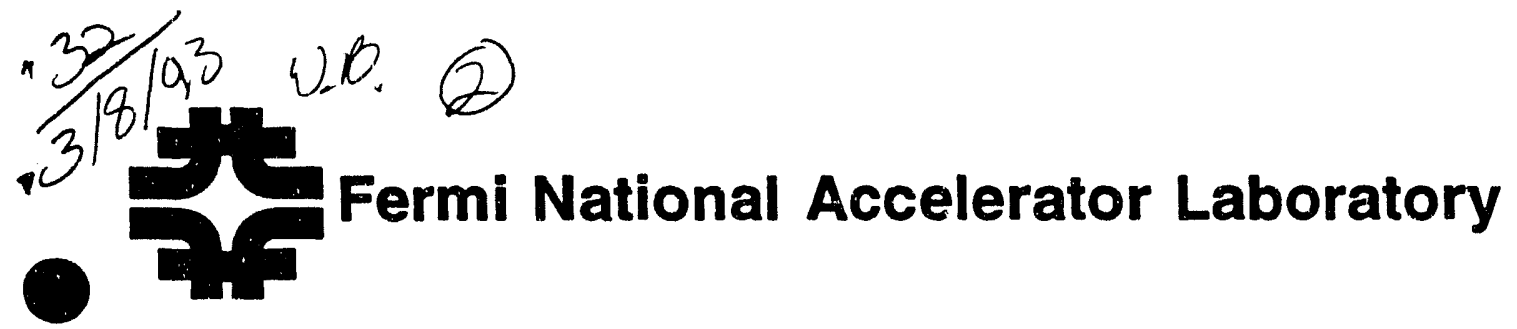

\title{
The Evolution of Cryogenic Safety at Fermilab
}

\author{
R. Stanek and J. Kilmer \\ Fermi National Accelerator Laboratory \\ P.O. Box 500, Batruia, Illinois 60510
}

\section{DISCLAIMER}

\begin{abstract}
This report was prepared as an account of work sponsored by an agency of the United States
Government. Neither the United States Government employees, makes any warranty, express or implied nor any agency thereof, nor any of their bility for the accuracy, completeness, or usefulied, or assumes any legal liability or responsiprocess disclosed, or represents that its use would of any information, apparatus, product, or ence herein to any specific cort mercial product, not infringe privately owned rights. Refermanufacturer, or otherwise does not necessarily constitute or ice by trade name, trademark, mendation, or favoring by the United States Govenstitute or imply its endorsement, recomand opinions of authors expressed herein do not necessar any agency thereof. The views United States Government or any agency thereof nocessarily state or reflect those of the
\end{abstract}

December 1992

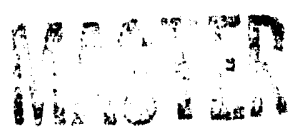




\section{Disclaimer}

This report was prepared as an account of work sponsored by an agency of the United States Government. Neither the United States Government nor any agency thereof, nor any of their employees, makes any warranty, express or implied, or assumes any legal liability or responsibility for the accuracy, completeness, or usefulness of any information, apparatus, product, or process disclosed, or represents that its use would not infringe privately owned rights. Reference herein to any specific commercial product, process, or service by trade name, trademark, manufacturer, or otherwise, does not necessarily constitute or imply its endorsement, recommendation, or favoring by the United States Government or any agency thereof. The views and opinions of authors expressed herein do not necessarily state or reflect those of the United States Government or any agency thereof. 


\title{
THE EVOLUTION OF CRYOGENIC SAFETY AT FERMILAB
}

\author{
R. Stanek and J. Kilmer \\ Fermi National Accelerator Laboratory* \\ P. O. Box 500, Batavia, IL 60510
}

\begin{abstract}
Over the past twenty-five years, Fermilab has been involved in cryogenic technology as it relates to pursuing experimentation in high energy physics. The Laboratory has instituted a strong cryogenic safety program and has maintained a very positive safety record. The solid commitment of management and the cryogenic community to incorporating safety into the system life cycle has led to policies that set requirements and help establish consistency for the purchase and installation of equipment and the safety analysis and documentation.
\end{abstract}

Keywords: Safety Program, Review, Policies

\section{INTRODUCTION}

Fermilab is the world's highest energy accelerator laboratory. Its mission is to find the ultimate building blocks of nature and to understand the forces acting on them. Fermilab is operated by Universities Research Association, a consortium of major research institutions, under the direction of the US Department of Energy. Fermilab adheres to all Federal, State and locid laws as well as DOE Orders in setting internal safety policies.

The principal scientific tool at Fermilab is the Tevatron, the world's first superconducting accelerator. ${ }^{1}$ The Tevatron was the proof of concept for the largescale use of cryogenics and superconducting technology in the field of high energy physics. A chronology of events for the Tevatron construction is presented in Table 1.

\footnotetext{
"Operated by the Universities Research Association, Inc. for the U.S. Department of Energy.
} 
It is apparent that, at least for this application of cryogenic technology, the progression from concept to implementation was extremely quick.

Superconducting magnet systems are just one of several applications for cryogenics at Fermilab. Liquid hydrogen targets, liquid argon calorimeters and bulk liquid storage for nitrogen gas purging systems are all incorporated into Fermilab's experimental program. Ten out of the total of fourteen fixed target beamlines had experiments that included a cryogenic system, see Table 2 for details. ${ }^{2}$ Both of the large collider experiments (CDF and $D \varnothing)$ have cryogenic systems integral to the detectors. 3,4

Fermilab conducts research so that personnel safety and the protection of the environment receive the highest consideration, while at the same time making the best use of laboratory facilities. Cryogenic safety receives particular attention because ryogenic systems have a significant potential for injury resulting from both technology-specific and common hazards. Cryogenic hazards include cold exposure, oxygen deficiency and trapped volume expansion problems. Electrical safety, hoisting and rigging, and safety while working around rotating machinery, are some of the more common problem areas. Coupling these types of hazards with a relatively new technology application creates a deserved cause for concern.

\section{EVOLUTION OF CRYOGENIC SAFETY}

Cryogenics played a key role at Fermilab even before the Tevatron was built. Cryogenic systems, in the form of liquid hydrogen bubble chambers and targets or as bulk liquid storage for nitrogen gas purging systems, were used in some of the first experiments. The use of liquid helium in conjunction with superconducting magnet systems has opened up a new realm of opportunities for experiments but has brought with it additional safety problems. The safety process has changed to keep up with these new challenges.

One of the first and largest cryogenic systems ever operated at Fermilab was the 15 Foot Hydrogen Bubble Chamber. The chamber itself held 30,000 liters of liquid hydrogen while the facility could stône a volume of roughly five times that amount. 
A superconducting ( 3 tesla) magnet provided the field for particle tracking. The system operated for 15 years and for 17 different experiments without a serious safety incident. The safety review process for the Bubble Chamber set the direction for the Lab-wide cryogenic safety program. It marked the first use of an external review committee to examine laboratory cryogenic activities. It also established an internal review committee that was the precursor to the Cryogenic Safety Subcommittee (CSS). The concept of frequent internal reviews, augmented by periodic external reviews, continues today.

Cryogenic safety has slowly evolved from an informal, satellite activity that occurred just before system start-up, to a quite rigorous, fully integrated part of the system life cycle. Initially, the cryogenic safety review was seen as a necessary hurdle to overcome on the way to getting a permit to operate the system. Cryogenic groups felt that given the intense engineering effort required for these systems and the self assessments which were part of the design process, all safety issues would already have been examined and any hazards already corrected. Slowly, this attitude changed as it became apparent that the process of being reviewed by an independent group of cryogenic engineers and safety professionals could contribute to better overall system efficiency and safety. Project engineers began to accept the idea that addressing questions raised by an unbiased and qualified review team would lead to a better engineered system. The safety process was seen as an aid to assuring completeness of the system and not as a "final test to pass."

Additionally, as the Laboratory matured, the number of different groups performing cryogenic work decreased. The need to have several groups pursuing a solution to a problem was surpassed by the desire to achieve uniformity. The benefits of consistency in design, analysis, choice of equipment and safety documentation started to become apparent. Once the key individuals, i.e., cryogenic group leaders, "bought into" the benefits of the cryogenic safety review process, this philosophy became self-perpetuating. 


\section{BUILDING A SUCCESSFUL SAFETY PROGRAM}

Institutionalizing the safety review process is more than writing policy and forcing implementation. For a cryogenic safety program to be effective, it needs the intellectual contributions of the most qualified, technical personnel and the acceptance, at all levels, of its importance. Cryogenic engineers active in designing and operating systems can be called upon to review the safety aspects of other systems. Since they are current with the state of the art in analysis and equipment, these engineers can help bring direction and a consistent approach to a particular problem. The Fermilab safety process, which includes peer review, establishes this sort of system.

Creating a safety conscious attitude in the workforce is an important and sometimes difficult challenge. Personnel, throughout the organization, must accept the positive aspects of the safety program and believe that worker and equipment safety is a primary concern. Building the proper attitude is a function of:

- demonstrating management's commitment to safety

- educating workers through training

- monitoring performance as it relates to safety

- rewarding safety consciousness in the workplace

Workers need to first see that management values safety. The attitude of the workforce is a reflection of the emphasis placed on safety by management. A token approach with inadequate support in terms of budget and personnel will yield subpar safety consciousness.

For a safety program to be successful, the five elements in Table 3 must be present. Long term safety starts with proper engineering and quality construction. There are many short-term physics or cryogenic engineering experiments where these elements are not quite as important. Although it is true that the hazards encountered can be the same and injuries may still occur, short duration tests are usually limited in scope. This implies that major modifications to the existing equipment during 
operation are not typical, operating procedures can be written ahead of time and total exposure time to hazards is finite and controllable.

Conversely, continuous process systems are highly dependent on quality construction since any type of failure means downtime. Failures result in "offnormal" operation and this increases the risk of injury. Long-term operation also can experience changing conditions, such as increasing heat loads. If the design does not incorporate these changes easily, "quick fixes" may develop. It is while a problem is thought to be solved temporarily and a final engineered solution is not yet implemented that safety may be compromised. Eleventh-hour solutions may work, but many times at the expense of a higher risk because of a lack of a thorough safety review.

All cryogenic systems need "qualified" operators to run them and troubleshoot problems. The process of qualifying individuals to operate can bring a deeper understanding of the complexities associated with the system. To maintain safety vigilance over the life of the project, operators must be trained to respond to situations properly. Most cryogenic systems will, at some time in their operation cycle, require the ingenuity and resourcefulness of the operators to "save the day." Operators need both formal and on-the-job training to gain the thorough understanding of the system needed to perform their duties safely and effectively.

Every cryogenic system should have a safety analysis performed on it by the system designers. The format of the analysis varies depending on the complexity and type of system. Common forms of analysis include hazard, failure mode and effects and what-if. Although the format may be different, the results are a thorough examination of the cryogenic process and equipment and the hazards associated with them.

Operating and maintenance procedures are critical parts of a well-rounded safety program. The act of writing procedures can be very enlightening; documenting the step-by-step actions by which a task is performed can be the best check of all on the adequacy of the design. Procedures should be comprehensive and 
sufficiently detailed that they can be executed in a straightforward manner by personnel adequately trained in them.

A successful safety program has in place a system of checks and balances. Written policies and standards form the basis for the program. However, it is up to an independent reviewer to determine how well the policies have been implemented for the specific system. The experience at Fermilab has led to the belief that the use of a peer group of cryogenic engineers supplemented by a safety professional makes a good team to perform this review. There are several benefits to this system, including:

Increased communication among on-site cryogenic engineers

Shared experiences and solutions

Highly qualified review teams with diverse backgrounds

\section{FERMILAB'S CRYOGENIC SAFETY SUBCOMMITTEE}

In order to design, construct and operate the cryogenic systems for the physics program at Fermilab safely and efficiently, a formal safety process has been set up. Each cryogenic installation is assigned a safety review panel usually consisting of three or four cryogenic, mechanical or electrical engineers and a conventional safety representative. The charge to the panel is to review and audit the safety documentation submitted by the responsible project engineers for compliance with established policies and standards; and to recommend to the responsible division head that the system is ready for operation. The division head then issues a permit to operate. The safety panel stays in place as long as the system is active. They inspect the installation periodically, check the documentation when upgrades are made, and become involved in the investigation of any cryogenic safety related incidents. Presently there are fifteen safety panels reviewing systems or areas at Fermilab.

All safety review panel chairmen automatically become members of the Cryogenic Safety Subcommittee (CSS), an organization that reports directiy to the Laboratory Safety Committee and the Direct.orate. The CSS meets monthly to discuss the status of the safety reviews, share experiences and develop or modify cryogenic 
safety policy as required. The meetings are a forum for providing consistency to the safety review process. Panel chairmen typically serve longer terms, often staying with the project through its lifetime. However, panel members are rotated as required to provide a fresh look at the systems and still maintain a continuous knowledge base of the installation. Members of the CSS can be called upon to consult with the project teams and pass on the benefits of their years of experience.

\section{STANDARDS AND POLICIES}

Fermilab's safety policy is laid out in its Environmental Safety and Health Manual. 5 The scope of topics covered by specific policy is inclusive and contains roles and responsibilities, safety training requirements, occupational safety and health, fire safety, construction safety and environmental protection. Radiation safety is covered in a separate manual. The policies and standards that specifically address cryogenic concerns are found in chapters entitled:

\section{Cryogenic System Review \\ Pressure Vessels \\ Vacuum Vessels \\ Pressure Vessel Testing \\ Pressure Piping Systems \\ Oxygen Deficiency Hazards}

The chapter on Cryogenic System Review is the policy statement that sets the scope for the safety review panels of new cryogenic installations. It also specifies the safety documentation that must be prepared as part of the Safety Report: system descriptions, flow schematics and valve lists, operating procedures, operator training and qualifications, failure mode and effects analysis and hazard or what-if analysis. Additional material may be required by the panel based on the nature of the specific project.

The Pressure and Vacuum Vessel chapters are applicable to both room temperature and cryogenic vessels. The American Society of Mechanical Engineers (ASME) Pressure Vessel Code Section VIII and the Compressed Gas Association 
Standards form the basis for these policies. The Laboratory adheres to these standards as much as possible in a research environment. The Pressure Vessel Testing policy uses the ASME rules as the guidance for procedural actions and requires documentation and a safety inspection of the test set up.

The problem of oxygen being displaced by large volumes of inert gases generated by the vaporization of cryogenic liquids is both serious and real. As Fermilab developed its cryogenic systems, it became apparent that there was a need to addres; this oxygen deficiency hazard. Al! cryogenic systems are now assessed for this hazard. The Fermilab methodology for analyzing a possible ODH environment incorporates a "quantitative assessment of the increased risk of fatality from potential exposure to reduced atmospheric oxygen." The ODH fatality rate is defined as:

$$
\varnothing=P_{i} F_{i}
$$

where:

$$
\begin{aligned}
& \emptyset=\text { the ODH fatality rate (per hour) } \\
& \mathrm{P}_{\mathrm{i}}=\text { the expected rate of the occurrence (per hour) } \\
& \mathrm{F}_{\mathrm{i}}=\text { the fatality factor for the occurrence }
\end{aligned}
$$

The total fatality rate is the summation over all possible events that could lead to an $\mathrm{ODH}$ condition. When possible, the probability factor is determined by operating experience at Fermilab, otherwise data from similar systems elsewhere is used. The fatality rate is a function of the lowest achievable partial pressure of oxygen, which depends on the enclosed volume, ventilation rate and maximum leak rates. The fatality rate determines the ODH class ( 0 through 4$)$ of the installation and impacts the control measures required.

\section{DIRECTION FOR THE FUTURE}

Fermilab is continually updating its cryogenic safety program to keep it in compliance with new and revised government regulations, DOE Orders and Best Management Practices. Several new chapters are in the process of being added to the 
ES\&H Manual. These include policies on: relief valve testing, LN2 dewar installations, transporting cryogenic dewars and guidelines for hydrogen targets. Additionally, the Laboratory and the DOE are in the process of formalizing the programs for Conduct of Operations and Maintenance activities. Both of these topics have strong ramifications for cryogenic systems.

The safety review process is continually evolving. The rules that are currently in place at Fermilab offer a strong basis for complete and consistent safety review of a cryogenic system. However, as the Laboratory matures, additional policy will be set that produces a more standardized environment 'while still preserving the necessary individualism of the many different projects that are brought on line.

\section{CONCLUSION}

Fermilab has operated crycgenic systems since the early days of its inception. During this time, there have bsen no serious cryogenic safety incidents. Fermilab has in place a system for crycogenic safety review that includes an independent peer review. The advantages of utilizing experienced cryogenic engineers as part of the review team far outweigh the cost of time demands on the staff.

The experience at Fermilab has led to the following conclusions:

- Successful cryogenic safety programs start with strong management commitment and support.

- Design, construction, analysis, trained operators and independent review all play key roles in the system safety life cycle.

- A positive workers' attitude towards safety may be the most vital area in need of attention and the most critical one to establish. 


\section{REFERENCES}

1 US Department of Energy, Unpeeling the nucleus of the atom, DOE This Month (April 1991) Vol. 14 No. 4, 8-9

2 Stanek, R. , Schmitt, R. and Urbin, J., Design, performance and reliability of cryogenic systems for the Fermilab fixed target program, Pruceedings of the XVIII International Congress of Refrigeration (1991) Vol. $3975-980$

3 Fast, R. et al., Testing of the superconducting solenoid for the Fermilab Collider Detector, Advances in Cryogenic Engineering (1985) Vol. 31 181-190

4 Mulholland, G. et al., Cryogenic design of the D-Zero Liquid Argon Collider Calorimeter, Advances in Cryogenic Engineering (1987) Vol. 33 1121-1127

5 Fermilab ES\&H Section, Fermilab Environment, Safety and Health Manual, Internal document 
TABLE 1

\section{Chronology of events}

\begin{tabular}{|l|l|}
\hline Jan 1967 & AEC/URA sign contract for Fermilab construction \\
\hline Mar 1971 & Tevatron concept introduced \\
\hline Mar 1972 & $200 \mathrm{GeV}$ achieved/ Bubble Chamber operates \\
\hline May 1976 & $500 \mathrm{GeV}$ achieved \\
\hline Jul 1979 & Tevatron construction authorized \\
\hline Apr 1983 & Beam in Tevatron \\
\hline Jul 1983 & $512 \mathrm{GeV}$ achieved \\
\hline Feb 1984 & $800 \mathrm{GeV}$ achieved \\
\hline Oct 1985 & Collisions at CDF $(1.6 \mathrm{TeV})$ \\
\hline Oct. 1986 & $900 \mathrm{GeV}$ achieved \\
\hline
\end{tabular}


TABLE 2

Overview of Cryogenic System Design Parameters

\begin{tabular}{|c|c|c|}
\hline Exp/System & Cryo System & Parameters \\
\hline \multirow[t]{3}{*}{ 665/NMS } & CERN Vertex Magnet (CVM) & $\begin{array}{l}2.0 \mathrm{~m} \text { dia. } \times 1.0 \mathrm{~m} \text { length (Bore) } \\
1.5 \mathrm{~T} @ 5000 \mathrm{~A} \text {, forced flow, } .1 \mathrm{~kg} / \mathrm{s}\end{array}$ \\
\hline & Chicago Cyclotron Magnet (CCM) & $\begin{array}{l}5.2 \mathrm{~m} \text { dia. } \times 1.9 \mathrm{~m} \text { length (Bore) } \\
1.5 \mathrm{~T} @ 750 \mathrm{~A} \text {, pool boiling } 6.2 \mathrm{~L} / \mathrm{h}\end{array}$ \\
\hline & LH2 \& LD2 Targets & $\begin{array}{l}0.1 \mathrm{~m} \text { dia. } \times 1.0 \mathrm{~m} \text { length } \\
50 \text { W APD, GM Refrigerato }\end{array}$ \\
\hline 683/PB7 & LH2 Target & $\begin{array}{l}.076 \mathrm{~m} \text { dia. } \times 0.5 \mathrm{~m} \text { length } \\
2-10 \mathrm{~W} \text { APD, GM Refrigerator }\end{array}$ \\
\hline \multirow[t]{2}{*}{ 687/PS4 } & 5 Dipole \& 4 Quadrupole Magnets & $\begin{array}{l}.07 \mathrm{~m} \text { dia } \times 6.4 \mathrm{~m} \text { length (Bore) } \\
4.5 \mathrm{~T} \bigcirc 4500 \mathrm{~A} \text {, forced flow }\end{array}$ \\
\hline & $\overline{L D_{2} \text { Target }}$ & $\begin{array}{l}.05 \mathrm{~m} \text { dia. } \times 3.4 \mathrm{~m} \text { length } \\
\text { LH2 Transfer Fluid } \\
\text { 3-10 W APD, GM Refrigerator }\end{array}$ \\
\hline 690/NEE & $\mathrm{LH}_{2}$ Target & $\begin{array}{l}.04 \mathrm{~m} \text { dia. } \times .14 \mathrm{~m} \text { length } \\
10 \mathrm{~W} \text { APD, C U Refrigerator }\end{array}$ \\
\hline \multirow[t]{3}{*}{ 704/MCC } & 7 Dipole Magnets & $\begin{array}{l}.07 \mathrm{~m} \text { dia } \times 6.4 \mathrm{~m} \text { length (Bore) } \\
4.5 \mathrm{~T} @ 4500 \mathrm{~A} \text {, forced flow }\end{array}$ \\
\hline & $\mathrm{LH}_{2}$ Target & $\begin{array}{l}.06 \mathrm{~m} \text { dia. } \times 1.0 \mathrm{~m} \text { length } \\
2-10 \mathrm{~W} \text { APD, GM Refrigerators }\end{array}$ \\
\hline & Polarized Proton System & $\begin{array}{l}80 \mathrm{mK} \& 500 \mathrm{mK} \text { operation } \\
.09 \mathrm{~m} \text { dia. } \times .56 \mathrm{~m} \text { length (Solenoid) } \\
6.5 \mathrm{~T} @ 183 \mathrm{~A} . \text { pool boiling }\end{array}$ \\
\hline \multirow[t]{3}{*}{$706 / \mathrm{MCC}$} & 3 Dipole Magnets & $\begin{array}{l}.07 \mathrm{~m} \text { dia } \times 6.4 \mathrm{~m} \text { length (Bore) } \\
4.5 \mathrm{~T} @ 4500 \mathrm{~A} \text {, forced flow }\end{array}$ \\
\hline & LH? Target & $\begin{array}{l}.06 \mathrm{~m} \text { dia. } \times .15 \mathrm{~m} \text { dia. length } \\
\text { LHe cooled using } 500 \text { L dewars }\end{array}$ \\
\hline & LA Calorimeter & 70,000 liter volume, $L N_{2}$ Recondenser \\
\hline 740/NWA & LA Calorimeter & 30,000 liter volume, $\mathrm{LN}_{2}$ Recondenser \\
\hline $771 /$ PS1 & 5 Dipole Magnets & $\begin{array}{l}.07 \mathrm{~m} \text { dia } \times 6.4 \mathrm{~m} \text { length (Bore) } \\
4.5 \mathrm{~T} \bigcirc 4500 \mathrm{~A} \text {, forced flow }\end{array}$ \\
\hline $782 / T B C$ & Tohoku Bubble Chamber Magnet & $\begin{array}{l}1.2 \mathrm{~m} \text { dia. } \times 1.4 \mathrm{~m} \text { length (Bore) } \\
1.2 \mathrm{~T} @ 700 \mathrm{~A} \text {, pool boiling }\end{array}$ \\
\hline $789 / \mathrm{MCC}$ & 16 Dipole Magnets & $\begin{array}{l}.07 \mathrm{~m} \text { dia } \times 6.4 \mathrm{~m} \text { length (Bore) } \\
4.5 \mathrm{~T} \bigcirc 4500 \mathrm{~A} \text {, forced flow }\end{array}$ \\
\hline $791 /$ PS4 & 1 Dipole \& 5 Quadrupole Magnets & $\begin{array}{l}.07 \mathrm{~m} \text { dia } \times 6.4 \mathrm{~m} \text { length (Bore) } \\
4.5 \mathrm{~T} @ 4500 \mathrm{~A} \text {, forced flow }\end{array}$ \\
\hline
\end{tabular}


Table 3

Elements of a Successful Cryogenic Safety Program

- Proper Design (Including preparation for unexpected)

- Quality Construction

- Qualifind Operators

- Comprehensive analysis and procedures

- Independent Review 
SENIOR AUTHOR:

Richard P. Stanek

Research Division/Cryogenics Department Head

Fermilab

P. O. Box 500

Batavia, IL 60505 

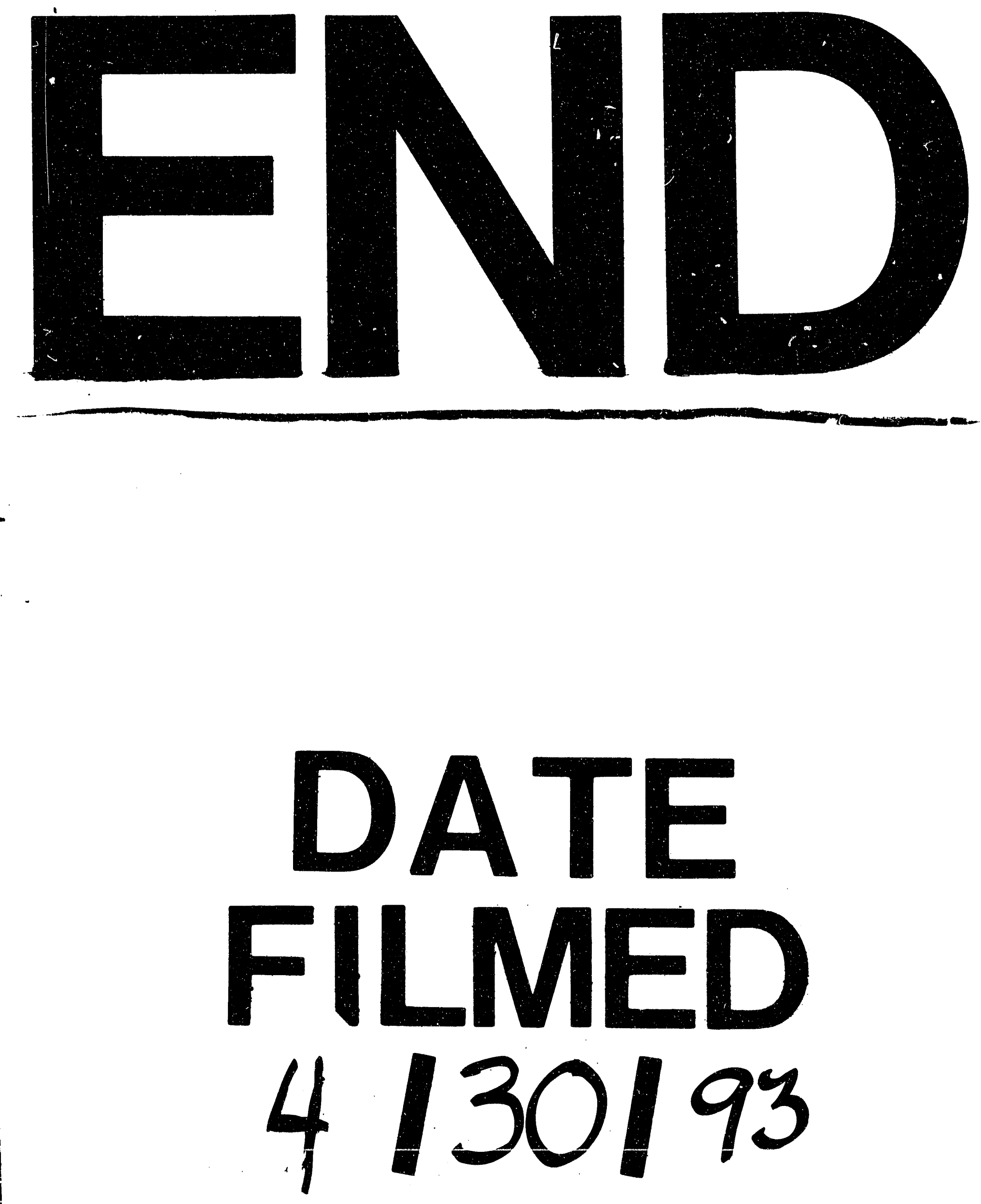
d 